\title{
A Composite Reliability Index for Power Distribution System in Renewable Microgrid Penetrated Energy Market
}

\author{
Tuhin Shubra Das, Parthasarthi Bera, Papun Biswas
}

\begin{abstract}
High penetration of renewable micro-grids in power distribution system has given rise to unique reliability issues owing to their intermittent nature. Moreover, individual reliability indices of power distribution systems tend to present conflicting results. Therefore, a single index to quantify the overall reliability of substations is necessary. In essence, this work proposes a Composite Reliability Index (CRI) for renewable penetrated Indian power distribution system. In this work, reliability indices are normalized using Z-scores, followed by Principal Component Analysis (PCA) for weight decision. Particularly, indices recommended in IEEE Std 1366-2003 and practiced by Indian utilities in real-time are studied. Finally, results of test-systems data analysis show that proposed CRI can expedite the reliability assessment process in multiple permutations of systems and operational choices.
\end{abstract}

Keywords : Data Analytics, Distribution System, Ranking, Reliabilty, Statistics.

\section{INTRODUCTION}

The potential impact of the power system's reliability on the socio-economic ecosystem [1], has compelled Indian utilities and regulators to address it sincerely. Furthermore, the penetration of renewable micro-grids has a huge impact on power distribution reliability [2]. Yet there exists no benchmark for peer comparison of substation's reliability [3]. Notably, existing system of assessing power distribution reliability is ambiguous owing to its "multi indices" approach [4]. Nevertheless, power distribution companies (Discoms) and authorities around the world have settled for reporting of four indices, namely SAIFI, SAIDI, CAIDI and ASAI [5]. However, there exist no common consensus on using any particular indices as a yardstick of measuring power distribution reliability, to cross-compare reliability performance of two different distribution systems. Even though peer comparison of distribution systems reliability is practiced regularly both by utilities and regulators [6] [7].

India's Central Electricity Authority (CEA) has recommended state Discoms to report SAIFI, SAIDI, CAIDI

Revised Manuscript Received on July 22, 2019.

Tuhin Shubra Das, Electrical Engineering department, JIS College of Engineering, Kalyani, India.

Parthasarthi Bera, Kalyani Government Engineering College, Kalyani, India.

Papun Biswas, Electrical Engineering department, JIS College of Engineering, Kalyani, India. and MAIFI in 2017 [8]. Although, India's CEA itself has reported SAIFI, SAIDI, and ASAI but excluded CAIDI in its reports till 2016 [9], [10]. In contrast, Discoms of observed Indian states (Maharashtra [11], West Bengal [12], Karnataka [13]) have opted to report SAIFI, SAIDI, CAIDI only, excluding ASAI in their data till 2018.

Creating a single Score/Index from a set of individual indicators demands a strong statistical approach. For development of composite index, literatures [14], [15] suggests of axioms rather than rigid rules. Notably, one of the pioneering work in unifying the distribution reliability indices proposes a customer survey based approach [16]. But the methodology has validity for a limited region and a set of specific indices. Alternatively, "public or expert opinion" based approaches such as AHP [17], [18] depends on knowledge and operational experience of experts. However, experts might not be readily available at every time and place to give feedback and opinions. Furthermore, "cost" based approaches for example reliability worth assessment technique [19], suffers exclusive dominance of economic factors.

Existing "multi indices" system give conflicting results to both regulatory bodies and distribution designers. In contrast, a single Composite Reliability Index (CRI) can facilitate a transparent assessment of substation's performance and improve utilities strategies to address the reliability issues of the distribution system in a deregulated energy market. This paper introduces the application of Z-score [15] and Principal Component Analysis (PCA) [21] to obtain a CRI for renewable penetrated power distribution system, according to their reliability indices data.

\section{PROCEDURE OF CRI FORMULATION}

\section{A. Normalization}

Data normalization is necessary to transform all variables in the data to a specific range. This paper employs Z-score approach for data normalization. But normal Arithmetic Mean (AM) based approach to find Z-score is sensitive to the presence of outliers in the data. A robust alternative to find the Z-score is a median based approach owing to its inertness to outliers [20]. Mathematically, these two methods are represented as below. 
Method 1: By Arithmetic Mean of data distribution : The standard score or the Z-score, of a raw score $x_{i}$ is represented by $Z_{a}$, and for a population of $N$ observations is given by

$$
Z_{a}=\frac{x_{i}-\mu_{a}}{\sigma_{a}}=\frac{x_{i}-\bar{x}}{\sigma_{a}}
$$

where $\mu_{a}$ is the Arithmetic Mean $(\bar{x})$ Of the population, and $\sigma_{a}$ is the Standard Deviation (SD) of the population, given by

$$
\sigma_{a}=\sqrt{\frac{\sum_{i=1}^{N}\left(x_{i}-\bar{x}\right)^{2}}{N}}
$$

Therefore, for an observed population of $N$ number of substations, if the reliability indices are given by, $x l_{i}=$ SAIFI $_{\mathrm{i}}^{\text {th }}$ Sub.Stn $; x 2_{i}=$ SAIDI $_{\mathrm{i}}^{\text {th }}$ Sub.Stn $; x 3_{i}=$ CAIDI $_{\mathrm{i}}^{\text {th }}$ Sub.Stn $;$ and $x 4_{i}$ $=$ ASAI $_{i}^{\text {th }}$ Sub.Stn; then the Z-score of observed indices (for ex. $\mathrm{SAIFI)}$ is given by:

$\mathrm{Z}_{\mathrm{a}}$ Score of $\left(\mathrm{SAIFI}_{\mathrm{i}}^{\mathrm{th}}\right.$ Sub.Stn $)=\left(\mathrm{SAIFI}_{\mathrm{i}}^{\mathrm{th}} \operatorname{Sub} . \operatorname{Stn}-\mu 1_{a}\right) / \sigma l_{a}$

Where

$\mu 1_{a}=$

Arithmetic mean of all $N$ number of SAIFIs observed,

$\sigma 1_{a}=$

$\sqrt{\left\{\left(\mathrm{SAIFI}_{1^{t} \text { sub.Stn }}-\mu 1_{a}\right)^{2}+\cdots+\left(\mathrm{SAIFI}_{N^{t h}} \text { Sub.Stn }-\mu 1_{a}\right)^{2}\right\} / N}$

Method 2: By Median of data distribution : Since Median and the Median Absolute Deviation (MAD) are insensitive to outliers, hence normalization employing Median and MAD is more robust [20]. The Robust Z-score of a raw score $x_{i}$ is represented by $R o b-Z$ and for a population of $N$ observations is given by

$$
R o b-Z=\frac{x_{i}-\mu_{m}}{\sigma_{m}}=\frac{x_{i}-\tilde{x}}{M A D \times 1.4826}
$$

where $\mu_{m}$ is Median ( $\left.\tilde{x}\right)$ of the population, and $\sigma_{m}$ is Median Absolute Deviation (MAD) of the population, given by

$$
\sigma_{m}=M A D \times 1.4826
$$

Where $M A D=$ Median $\left(\mid x_{i}-\right.$ Median $\left.x_{1 \ldots N} \mid\right)$, therefore

$$
\sigma_{m}=\text { Median }\left(\mid x_{i}-\text { Median } x_{1 \ldots N} \mid\right) \times 1.4826
$$

Therefore, for an observed population of $N$ number of substations, if the reliability indices are given by, $x l_{i}=$ SAIFI $_{\mathrm{i}}^{\text {th }}$ Sub.Stn $; x 2_{i}=$ SAIDI $_{\mathrm{i}}^{\text {th }}$ Sub.Stn $; x 3_{i}=$ CAIDI $_{\mathrm{i}}^{\text {th }}$ Sub.Stn ; and $x 4_{i}=\mathrm{ASAI}_{\mathrm{i}}^{\mathrm{th}}$ Sub.Stn ; then $R o b-Z$ of observed indices (for ex. $\mathrm{SAIFI)}$ is given by:

$R o b-Z 1_{\mathrm{m}}$ of $\left(\mathrm{SAIFI}_{\mathrm{i}}^{\mathrm{th}}\right.$ Sub.Stn $)=\left(\mathrm{SAIFI}_{\mathrm{i}}^{\mathrm{th}} \operatorname{Sub.Stn}-\mu 1_{m}\right) / \sigma 1_{m}$ Where

$\mu 1_{m}=$ Median of all $N$ number of SAIFIs observed

$\sigma l_{m}=\operatorname{Median}\left(\left|\left(\operatorname{SAIFI}_{i^{t h} \text { Sub.Stn }}\right)_{i=1 \ldots N}-\mu 1_{m}\right|\right) \times 1.4826(11)$

\section{B. Weightage \& Aggregation}

There's no universal consent on weight allocation and aggregation approaches of individual indicators [15]. This paper, is employing PCA for weight allocation of Z-score normalized data, followed by aggregation employing a simple additive approach.

\section{Data Analysis \& Results}

For the purpose of analysis three different datasets have been collected from the Central Electricity Authority (CEA) of India for the year 2015 and 2016, and Maharashtra's MAHADISCOM data of March 2018. Indian CEA's data is missing CAIDI in its reports, while MAHADISCOM's reported data is missing ASAI. Accordingly, CAIDI of CEA's data is calculated using the formula given in [4], [6].

$$
\text { CAIDI }=\text { SAIDI } / \text { SAIFI }
$$

Similarly, ASAI of MAHADISCOM's data is calculated using the formula given in [4], [6] but with modification in terms of monthly calculations, and is given by

$$
A S A I=\frac{N_{T} * \text { Number of Hours per month }-\sum r_{i} N_{i}}{N_{T^{* N u m b e r} \text { of Hours per month }}}
$$

Next, normalization of data is done by finding $Z_{\mathrm{a}}$ score and Rob- $Z$ of each dataset. Finally, PCA of the normalized data is performed using IBM SPSS 25 . Three scenarios are considered for study and analysis of data, as described below

Scenario 1: PCA of SAIFI, SAIDI, ASAI

Scenario 2: PCA of SAIFI, SAIDI, CAIDI

Scenario 3: PCA of SAIFI, SAIDI, CAIDI, ASAI

To investigate the overall statistical quality of correlation and sampling adequacy of the data the Measure of Sampling Adequacy (MSA) score of Anti-Image Matrix and Kaiser-Meyer-Olkin (KMO) scores are consulted for every dataset. Any dataset having a MSA and KMO score below 0.500 is unacceptable. Also, the more a dataset has a MSA and KMO score nearer to 1 the better will be its acceptance for sampling [21]. Table 1 shows the corresponding Anti-Image MSA scores of the dataset of above described CEA's 2015, 2016 data and MAHADISCOM's March 2018 data.

Table 2 shows the Kaiser-Meyer-Olkin (KMO) measure of sampling adequacy of CEA's normalized reliability data for the years of 2015 and 2016; and MAHADISCOM's normalized reliability data of March 2018.

Arithmetic Z-scores $\left(Z_{a}\right)$ and $R o b-Z$ for SAIDI, CAIDI and ASAI can be deduced in similar manner.

Table 1: Anti-Image MSA scores 


\begin{tabular}{|c|c|c|c|c|c|c|c|}
\hline \multicolumn{4}{|c|}{ Case 1 - AM based $Z_{\mathrm{a}}$ Score's MSA } & \multicolumn{4}{|c|}{ Case 2 - Robust. Zscore's MSA } \\
\hline & 2015 & 2016 & 2018 & & 2015 & 2016 & 2018 \\
\hline SAIFI $Z_{a}$ & 0.600 & 0.791 & 0.987 & SAIFI RobZ & 0.600 & 0.791 & 0.990 \\
\hline SAIDI $_{a}$ & 0.786 & 0.722 & 0.527 & SAIDI RobZ & 0.786 & 0.722 & 0.526 \\
\hline ASAI $Z_{a}$ & 0.604 & 0.785 & 0.527 & ASAI RobZ & 0.604 & 0.785 & 0.526 \\
\hline \multicolumn{8}{|c|}{ Scenario 2} \\
\hline \multicolumn{4}{|c|}{ Case 1 - AM based $Z_{\mathrm{a}}$ Score's MSA } & \multicolumn{4}{|c|}{ Case 2 - Robust. Zscore's MSA } \\
\hline & 2015 & 2016 & 2018 & & 2015 & 2016 & 2018 \\
\hline SAIFI $\mathrm{Z}_{\mathrm{a}}$ & 0.621 & 0.427 & 0.317 & SAIFI RobZ & 0.621 & 0.427 & 0.322 \\
\hline SAIDI Z $_{a}$ & 0.518 & 0.405 & 0.156 & SAIDI RobZ & 0.518 & 0.405 & 0.166 \\
\hline CAIDI Z $_{a}$ & 0.522 & 0.197 & 0.303 & CAIDI RobZ & 0.522 & 0.197 & 0.309 \\
\hline \multicolumn{8}{|c|}{ Scenario 3} \\
\hline \multicolumn{4}{|c|}{ Case 1 - AM based $Z_{a}$ Score's MSA } & \multicolumn{4}{|c|}{ Case 2 - Robust. Zscore's MSA } \\
\hline & 2015 & 2016 & 2018 & & 2015 & 2016 & 2018 \\
\hline SAIFI $Z_{a}$ & 0.527 & 0.647 & 0.457 & SAIFI RobZ & 0.527 & 0.647 & 0.446 \\
\hline SAIDI Z $_{a}$ & 0.553 & 0.631 & 0.514 & SAIDI RobZ & 0.553 & 0.631 & 0.505 \\
\hline ASAI $Z_{a}$ & 0.603 & 0.832 & 0.521 & ASAI RobZ & 0.525 & 0.832 & 0.511 \\
\hline CAIDI Z $_{\mathrm{a}}$ & 0.525 & 0.247 & 0.414 & CAIDI RobZ & 0.603 & 0.247 & 0.400 \\
\hline
\end{tabular}

Table 2: KMO scores

\begin{tabular}{|c|l|l|l|l|}
\hline & & 2015 & 2016 & 2018 \\
\hline Scenario No. & Case No. & KMO & KMO & KMO \\
\hline \multirow{2}{*}{ Scenario 1 } & Case1- $Z_{\mathrm{a}}$ score & 0.634 & 0.764 & 0.551 \\
\cline { 2 - 5 } & Case2- Rob-Z & 0.634 & 0.764 & 0.549 \\
\hline \multirow{2}{*}{ Scenario 2 } & Case1- $\mathrm{Z}_{\mathrm{a}}$ score & 0.530 & 0.378 & 0.271 \\
\cline { 2 - 5 } & Case2- Rob-Z & 0.530 & 0.378 & 0.278 \\
\hline \multirow{2}{*}{ Scenario 3 } & Case1- $\mathrm{Z}_{\mathrm{a}}$ score & 0.550 & 0.643 & 0.486 \\
\cline { 2 - 5 } & Case2- Rob-Z & 0.550 & 0.643 & 0.476 \\
\hline
\end{tabular}

Above analysis of the CEA and MAHADISCOM data shows that CAIDI is responsible for low values of both KMO score and Anti-Image MSA scores. Hence, it should be excluded from PCA analysis of reliability data. Thus Scenario 1 is the best choice for calculating CRI. Furthermore, PCA of Scenario 1 reduces three variables into a single component with a cumulative total variance of more than $60 \%$ for each dataset. Therefore, individual component score of PCA [22] gives CRI for a given substation. It appears on testing that substation with lowest CRI score is "best" in terms of overall reliability while highest CRI scoring substation is "worst" in terms of overall reliability.

It is worth noting at this point that our analysis of Indian distribution system data reflects that both arithmetic Z-score and Rob- $Z$ are showing equal results of KMO score. These results appeared because the data sets are very large. But the efficiency of Rob-Z lies in the fact that it can predict outliers even in very small data sets.

\section{TESTING \& VERIFICATION}

Since real time indices data are massive and bewildering, two "Test Systems" indices data has been chosen, as given in [2] and [23]. Both test systems have presented six case studies, with "Base Case / 1st Case" as worst case and "Last Case / 6th Case" as the best case according to the scores of individual reliability indices.

In the first place, the efficacy of Rob- $\mathrm{Z}$ over $\mathrm{Z}_{\mathrm{a}}$-Score on Test Systems (TS) data is examined to avoid miscalculation of CRI in the presence of outliers. Table 3 shows data as given in Test system 1 [2] and Test system 2 [23]. For sake of simplicity only SAIDI data is presented. Row 1 and 6 of Table 3 shows case studies of TS 1 and TS 2 respectively. Whereas, row 2 and row 7 shows a scenario where data has been corrupted due to human error or machine fault in each Test System. The corrupted entries are shown in bold italics in Table 3. Corresponding " $\mathrm{Z}_{\mathrm{a}}-\mathrm{S}$ core" and "Rob-Z" are shown in row 4,9 and row 5,10 respectively. Notably, the arithmetic mean based $\mathrm{Z}_{\mathrm{a}}$-Score is not able to weed out the outlier from the small sets of data provided. Contrarily, median based Rob- $\mathrm{Z}$ performed in a more robust manner and is able to weed out the outliers [20] from the same dataset.

Table 4 shows reliability indices data of Test system 1 as given in [2]. The data is given in reverse order, starting from worst scenario as Base Case and descending to best scenario as case $E$.

Table 4: Reliability Indices Data of Test System 1 [2]

\begin{tabular}{|c|c|c|c|c|c|}
\hline & SAIFI & SAIDI & CAIDI & ASAI & Given Rank \\
\hline Base Case & 0.9225 & 9.4586 & 10.2530 & 0.9989 & $\boldsymbol{6}^{\text {th }}-$ Worst \\
\hline Case A & 0.2635 & 9.1506 & 34.7240 & 0.9990 & 5 \\
\hline Case B & 0.2354 & 9.0191 & 38.3100 & 0.9990 & 4 \\
\hline Case C & 0.1909 & 8.3979 & 43.9880 & 0.9990 & 3 \\
\hline Case D & 0.1665 & 8.0070 & 48.0850 & 0.9991 & 2 \\
\hline Case E & 0.1601 & 7.7363 & 48.3340 & 0.9991 & $\boldsymbol{1}^{\text {st }}-$ Best \\
\hline
\end{tabular}

Table 4a shows the CRI score calculated by the proposed method in two choices of combination. Combination "CRI I" has SAIFI, SAIDI, ASAI with omitted CAIDI, Combination "CRI II" has SAIFI, SAIDI, CAIDI, ASAI. Both choices are calculated in weighted scenario as well as in Equal-weighted or Un-weighted scenario. 
A Composite Reliability Index for Power Distribution System in Renewable Microgrid Penetrated Energy Market

\begin{tabular}{|c|c|c|c|c|c|c|c|c|}
\hline Row 1 & & Base Case & Case A & Case B & Case C & Case D & Case E & \multirow{5}{*}{$\begin{array}{c}\text { Test } \\
\text { System } \\
1\end{array}$} \\
\hline Row 2 & SAIDI & 9.4586 & 9.1506 & 9.0191 & 8.3979 & 8.0070 & 7.7363 & \\
\hline Row 3 & Corrupt & 9.4586 & 9.1506 & 9.0191 & 4.3979 & 8.0070 & 7.7363 & \\
\hline Row 4 & $\mathrm{Z}_{3}$ Score & 0.8759 & 0.6957 & 0.6188 & -2.0851 & 0.0266 & -0.1318 & \\
\hline Row 5 & Rob-Z & 0.9019 & 0.6081 & 0.4827 & -3.9251 & -0.4827 & -0.7409 & \\
\hline Row 6 & & Case 1 & Case 2 & Case 3 & Case 4 & Case 5 & Case 6 & \multirow{5}{*}{$\begin{array}{c}\text { Test } \\
\text { System } \\
2\end{array}$} \\
\hline Row 7 & SAIDI & 0.7766 & 0.7565 & 0.7332 & 0.7202 & 0.6975 & 0.6895 & \\
\hline Row 8 & Corrupt & 0.8866 & 0.7565 & 0.7332 & 0.7202 & 0.6975 & 0.6895 & \\
\hline Row 9 & $\mathrm{Z}_{\mathrm{a}} \mathrm{Score}$ & 2.1070 & 0.1399 & -0.2124 & -0.4090 & -0.7522 & -0.8732 & \\
\hline Row10 & Rob-Z & 3.6560 & 0.6813 & 0.1486 & -0.1486 & -0.6676 & -0.8505 & \\
\hline
\end{tabular}

Table 4a: Calculated CRI scores from Reliability Indices Data of Table 4

\begin{tabular}{|c|r|r|r|r|}
\hline & UN-WTD_I & WTD_I & UN-WTD_II & WTD_II \\
\hline Base Case & 9.7499 & 10.6300 & 6.6305 & -14.4000 \\
\hline Case A & 1.2211 & 1.1116 & 0.5724 & -1.7156 \\
\hline Case B & 0.6751 & 0.6174 & 0.3885 & -0.8572 \\
\hline Case C & -0.6765 & -0.6187 & -0.3899 & 0.8586 \\
\hline Case D & -0.4769 & -2.3287 & 0.2233 & 2.7902 \\
\hline Case E & -0.8853 & -2.7056 & -0.1598 & 3.1374 \\
\hline Combination & \multicolumn{7}{|c|}{ CRI - I } & \multicolumn{1}{|c}{ CRI - II } \\
\hline
\end{tabular}

Table $4 \mathrm{~b}$ shows the proposed ranking according to the score achieved by each study case. It's clearly visible that the score of combination "CRI I" gives a distorted score in equal weight or un-weighted scenarios, while a PCA weighted score gives a perfect match of the ranking given in [2]. In contrast, Combination "CRI II" gives a fully distorted rank in both PCA weighed and unweighted scene.

Table 4b: CRI based proposed Ranking for Test System 1

\begin{tabular}{|c|c|c|c|c|}
\hline UN-WTD_I & WTD_I & UN-WTD_II & WTD_II & $\begin{array}{c}\text { Proposed } \\
\text { Rank }\end{array}$ \\
\hline Case C & Case E & Case C & Base Case & $\boldsymbol{I}^{\text {st }}$ - Best \\
\hline Case E & Case D & Case E & Case A & 2 \\
\hline Case D & Case C & Case D & Case B & 3 \\
\hline Case B & Case B & Case B & Case C & 4 \\
\hline Case A & Case A & Case A & Case D & 5 \\
\hline Base case & Base case & Base case & Case E & $\boldsymbol{6}^{\text {th }}$ - Worst \\
\hline Distorted & $\begin{array}{l}\text { Perfect } \\
\text { Match }\end{array}$ & Distorted & Distorted & \\
\hline \multicolumn{7}{|c|}{ CRI - I } & \multicolumn{2}{|c|}{ CRI - II } \\
\hline
\end{tabular}

Table 5 shows data as given in [23], this is the Test System 2 and the data is arranged in the same reverse ranking fashion as in Test system 1 above. To be noted ASAI is not given in [23], thus calculated using formula given in [4], [6].

Table 5: Reliability Indices Data of Test System 2 [23]

\begin{tabular}{|c|c|c|c|c|c|}
\hline & SAIFI & SAIDI & CAIDI & ASAI & $\begin{array}{c}\text { Given } \\
\text { Rank }\end{array}$ \\
\hline Case - 1 & 0.1355 & 0.7766 & 5.7330 & 0.999911 & $\boldsymbol{6}^{\text {th }}$ - Worst \\
\hline Case - 2 & 0.1303 & 0.7565 & 5.8070 & 0.999914 & 5 \\
\hline Case - 3 & 0.1243 & 0.7332 & 5.8990 & 0.999916 & 4 \\
\hline Case - 4 & 0.1210 & 0.7202 & 5.9500 & 0.999918 & 3 \\
\hline Case - 5 & 0.1152 & 0.6975 & 6.0550 & 0.999920 & 2 \\
\hline Case - 6 & 0.1132 & 0.6895 & 6.0910 & 0.999921 & $\boldsymbol{I}^{\text {st }}-$ Best \\
\hline
\end{tabular}

Table 5a below shows the CRI score calculated by the proposed method in two choices of combinations in the same fashion as in Table 4a calculations. Therefore, combination "CRI I" has SAIFI, SAIDI, ASAI with omitted CAIDI, while combination "CRI II" has SAIFI, SAIDI, CAIDI, ASAI. Both choices of combinations are calculated in weighted scenario as well as in Equal-weighted or Un-weighted scenario.
Table 5a: Calculated CRI scores from Reliability Indices Data of Table 5

\begin{tabular}{|c|c|c|c|c|}
\hline & UN-WTD_I & WTD_I & UN-WTD_II & WTD_II \\
\hline Case - 1 & 1.147974 & 3.429804 & 0.106321 & 4.470620 \\
\hline Case - -1 & 0.683424 & 2.046120 & 0.044290 & 2.684744 \\
\hline Case - 3 & 0.147405 & 0.444638 & 0.008700 & 0.583233 \\
\hline Case - 4 & -0.147405 & -0.444638 & -0.008700 & -0.583233 \\
\hline Case - 5 & -0.665557 & -2.000816 & 0.044290 & -2.710110 \\
\hline Case - 6 & -0.844230 & -2.545314 & 0.061437 & -3.450275 \\
\hline Combination & \multicolumn{6}{|c|}{ CRI - I } & \multicolumn{3}{c|}{ CRI - II } \\
\hline
\end{tabular}

Table $5 \mathrm{~b}$ shows the proposed ranking according to the score achieved by each study case. Score of combination "CRI I" gives a perfect match of the ranking given in [23] both in equal / un-weighted scenario, and PCA weighted scenario. In contrast, combination "CRI II" gives a distorted rank in unweighted scene, but a perfect match in PCA weighed scenario.

Table 5b: CRI based proposed Ranking for Test System 2

\begin{tabular}{|c|c|c|c|c|}
\hline $\begin{array}{c}\text { UN-W } \\
\text { TD_I }\end{array}$ & WTD_I & $\begin{array}{c}\text { UN-WTD } \\
\text { II }\end{array}$ & WTD_II & $\begin{array}{l}\text { Proposed } \\
\text { Rank }\end{array}$ \\
\hline Case 6 & Case 6 & Case 4 & Case 6 & $I^{s t}-B e s t$ \\
\hline Case 5 & Case 5 & Case 3 & Case 5 & 2 \\
\hline Case 4 & Case 4 & Case 2 & Case 4 & 3 \\
\hline Case 3 & Case 3 & Case 5 & Case 3 & 4 \\
\hline Case 2 & Case 2 & Case 6 & Case 2 & 5 \\
\hline Case 1 & Case 1 & Case 1 & Case 1 & $6^{\text {th }}-$ Worst \\
\hline $\begin{array}{l}\text { Perfect } \\
\text { Match }\end{array}$ & $\begin{array}{l}\text { Perfect } \\
\text { Match }\end{array}$ & Distorted & $\begin{array}{l}\text { Perfect } \\
\text { Match }\end{array}$ & \\
\hline \multicolumn{2}{|c|}{ CRI - I } & \multicolumn{2}{|c|}{ CRI - II } & \\
\hline
\end{tabular}

\section{Conclusion}

In this paper a new method to calculate the Composite Reliability Index (CRI), is proposed for renewable penetrated power distribution market of India, applying robust Zscore and PCA. The proposed CRI can not only evaluate overall reliability of different substations in a renewable penetrated environment facilitating peer comparison. But also it is capable of self-assessing the reliability of same substation to measure the impact of reliability improvement efforts done by utilities from time to time. Notably, the proposed CRI works in the reverse order i.e. a lower score of CRI depicts better overall reliability of the substation. Though, in this work the application of proposed CRI is considering SAIFI, SAIDI, CAIDI, and ASAI, but can be scaled to include any number of indices if required.

\section{REFERENCES}

1. Aklin. M, Bayer. P, Harish S. P., Urpelainen J.: "Does basic energy access, generate socioeconomic benefits? A field experiment with off-grid solar power in 
India", Science Advances 2017; 3: e1602153

2. Mathew. R. K, Ashok. S, Kumaravel. S.: "Analyzing the Effect of DG on Reliability of Distribution Systems", 2015 IEEE International Conference on Electrical, Computer and Communication Technologies (ICECCT)

3. Sindi. H, El-Saadany. E.: "Unified Reliability Index Development for Utility Performance Assessment", Intelligent Industrial System (2016) vol. 2, Springer Science + Business Media Singapore 2016, pp. 149-161

4. IEEE Std 1366"M-2003, "IEEE Guide for Electric Power Distribution Reliability Indices", Published by The Institute of Electrical and Electronics Engineers, Inc. New York, USA, ISBN 0-7381-3889-4 SH95193

5. Billinton. R and Allan. R.N: "Reliability of Electric Power Systems: An Overview", Handbook of Reliability Engineering, 511-527, Springer-2003, ISBN 1-85233-453-3

6. Chowdhury. A., Koval D.: Power Distribution System Reliability: Practical Methods and Applications, vol. 48. Wiley, New York (2011)

7. Brown. R.E.: Electric Power Distribution Reliability. CRC Press, Boca Raton (2008)

8. http://www.cea.nic.in/reports/others/god/pfa/rel index data for mat.pdf

9. http://www.cea.nic.in/reports/annual/reliabilityindices/rel_ind-2 015.pdf

10. http://www.cea.nic.in/reports/annual/reliabilityindices/rel_ind-2 $\underline{016 . p d f}$

11. https://www.mahadiscom.in/reliability-indices/

12. https://www.wbsedcl.in/webdynpro/dispatcher/local/SysiSyfiRe port/SaidiSaifiReport

13. https://bescom.org/reliability-index-of-power-supply/

14. Mazziotta. M, Pareto. A: "Methods for constructing composite indices: one for all or all for one?", Rivista Italiana di Economia Demografia e Statistica, Volume LXVII n. 2 April - June 2013 , pp. $67-80$

15. "Handbook on Constructing Composite Indicators: Methodology and User Guide", Joint Research Centre (JRC) of the European Commission, Ispra, Italy. OECD Publishing 2008.

16. Ortmeyer T.: "A unified index for power distribution reliability/power quality indices", IEEE Proceedings of 14th International Conference on Harmonics and Quality of Power (ICHQP), 1-6 (2010)

17. Lee, B., Kim, K.M., Goh, Y.: "Unified power quality index using ideal AHP". 13th International Conference on Harmonics and Quality of Power 2008, pp. 1-5 (2008).

18. Elbasuony GS, Abdel Aleem SHE, Ibrahim AM, Sharaf AM.: "A unified index for power quality evaluation in distributed generation systems", Energy (2018)

19. McGranaghan, M.F.: "Quantifying reliability and service quality for distribution systems", IEEE Trans. Ind. Appl. 43(1), pp. 188-195 (2007).

20. A. Nurunnabi, D. Belton, G. West.: "Robust Outlier Detection and Saliency Features Estimation in Point Cloud Data," International Conference on Computer and Robot Vision. IEEE 2013, pp. 98-105

21. Beavers. A. S., Lounsbury. J. W., Richards. J. K., Huck. S. W., Skolits. G. J. \& Esquivel. S. L.: "Practical Considerations for Using Exploratory Factor Analysis in Educational Research", Practical Assessment, Research \& Evaluation, Volume 18, Number 6, March 2013

22. Abeyasekera. S.: "Multivariate methods for index construction", United Nations Publication 2005, ST/ESA/STAT/SER.F/96, Sales No. E.05.XVII.6

23. Adefarati T, Bansal R.: "Reliability assessment of distribution system with the integration of renewable distributed generation". Applied Energy 2017, 185: pp. 158-71.

\section{AUTHORS PROFILE}

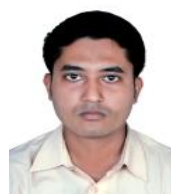

Tuhin Shubra Das received the B.E. degree in Electrical Engineering from University of Rajasthan, Jaipur, India in 2009 and M.tech degree in Electrical Devices \& Power System from Maulana Abul Kalam Azad University of Technology (formerly West Bengal University of Technology), Kolkata, India, in 2018. From 2009-16 he has worked as an Application engineer in many Indian organizations and MNCs. He has a proficiency in commissioning power control systems of captive power plants in various industrial environments.

Currently, he is a PhD student at Maulana Abul Kalam Azad University of Technology, Kolkata, India. His research interests include Distribution system Reliability, Distribution Automation, Microgrids, and applications of Data analytics on power systems.

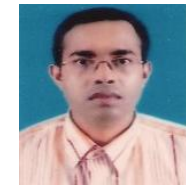

Parthasarthi Bera, received the B.E degree in Electrical Engineering from University of North Bengal, Siliguri, India, in 1999. A Master's degree in Power System from Jadavpur University, Kolkata, in 2001, and Ph.D. degree in Electrical Kharagpur, India, in 2007. Engineering from Indian Institute of Technology,

Currently, he is an Assisstant Professor of Electrical Engineering at Kalyani Government Engineering College, Kalyani, India. He has published over thirty high end research articles in various national and international journals. His research interests include Small Signal stability, Automatic Generation control, Power System Protection, power system dynamics, load frequency control, DFIG and applications of Artificial Intelligence on power systems.

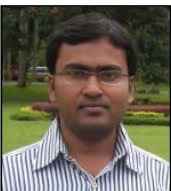

Papun Biswas, received the Ph.D. degree in Electrical Engineering from Kalyani University, Kalyani, India, in 2015. Prior to joining the academia he had an industrial expouser as project engineer for Maharatna PSU compines like NTPC. Currently, he is an Associate Professor and Head of the Department of Electrical Engineering at JIS College of Engineering, Kalyani, India. He is also TEQIP 1.2 Procurement Committee Nodal Officer and IEEE Student Branch Counselor at JISCE, Kalyani. His research interests include Multi-objective Optimization, Soft Computing Techniques, Power system control, Power system congestion management and energy efficiency. He is a member of the IEEE Computational Society and FOSET 